\title{
УЧЕТ ВЫШЕСТОЯЩИМ НАЛОГОВЫМ ОРГАНОМ НОВЫХ ДОКАЗАТЕЛЬСТВ И УСТАНОВЛЕНИЕ НОВЫХ ОБСТОЯТЕЛЬСТВ КАК СУЩЕСТВЕННОЕ ПРОЦЕДУРНО-ПРОЦЕССУАЛЬНОЕ НАРУШЕНИЕ ${ }^{1}$
}

\section{HIGHER TAX AUTHORITIES' CONSIDERATION OF NEW EVIDENCE AND ESTABLISHMENT OF NEW CIRCUMSTANCES OF THE CASE AS A SUBSTANTIAL PROCEDURAL VIOLATION}

\section{Zimulkin}

Summary. The author examines in detail the legal aspects related to the procedural issues of collecting and recording new evidence by the higher tax authority, as well as establishing new circumstances at the stage of the appeal consideration.

The author pays special attention to the problems of qualifying actions to collect and record new evidence when considering a complaint by a higher tax authority as significant procedural violations.

Based on the analysis of judicial practice and the provisions of the current legislation, the author concludes that the establishment by a higher tax authority of fundamentally new circumstances is recognized as a significant violation of procedural rules of tax legislation, which, as a rule, may entail the cancellation of the decision of the relevant tax authority.

The conclusions made by the author contribute to the improvement of law enforcement in a specific area of public relations and a decrease in the number of tax disputes related to procedural violations of tax authorities.

Keywords: tax, tax legal proceeding, tax procedure, tax procedural rules, tax control, tax violations, tax disputes.

\author{
Зимулькин Максим Игоревич \\ Преподаватель, Уральский государственный \\ юридический университет, г. Екатеринбург \\ mi.zimulkin@gmail.com
}

Аннотация. Автор подробно рассматривает правовые аспекты, связанные с процедурно-процессуальными вопросами сбора и учета вышестоящим налоговым органом новых доказательств, установлением новых обстоятельств на стадии рассмотрения апелляционной жалобы.

Особое внимание автор уделяет проблемам квалификации действий по сбору и учету новых доказательств при рассмотрении жалобы вышестоящим налоговым органом в качестве существенных процедурно-процессуальных нарушений.

На основе анализа судебной практики и положений действующего законодательства автор делает вывод о том, что установление вышестоящим налоговым органом принципиально новых обстоятельств признается существенным нарушением процедурно-процессуальных норм налогового законодательства, которое, как правило, может повлечь отмену решения соответствующего налогового органа.

Сделанные автором выводы способствуют совершенствованию правоприменительной деятельности в конкретной сфере общественных отношений и снижению количества налоговых споров, связанных с процедурно-процессуальными нарушениями налоговых органов.

Ключевые слова: налог, налоговое процедурное право, налоговый процесс, налоговые процедурно-процессуальные нормы, налоговый контроль, налоговые правонарушения, налоговые споры.
B рамках налогового контроля налоговый орган собирает доказательства, позволяющие установить конкретные факты хозяйственной деятельности налогоплательщика с целью выявления нарушений налогового законодательства (глава 14 НК РФ).
Собранные доказательства в своей системной взаимосвязи фиксируются в акте налоговой проверки (ст. 100 НК РФ), а затем, после ознакомления налогоплательщика с актом и получения от него возражений, исследуется руководством территориального налогового органа 
с целью принятия решения о привлечении налогоплательщика к ответственности, либо об отказе в привлечении (ст. 101 НК РФ).

На момент рассмотрения материалов проверки налоговый орган должен обладать достаточной для принятия решения доказательственной базой, что, допускает принятие на обозначенной стадии налоговой проверки решения о проведении дополнительных мероприятий налогового контроля.

Таким образом, принимающий решение налоговый орган обязан располагать достаточной совокупностью доказательств, а также, в случае реализации налогоплательщиком своих процедурно-процессуальных прав, быть осведомленным о позиции налогоплательщика относительно оснований вменяемого налогового правонарушения.

Изложенное соответствует позиции Конституционного Суда РФ [1] и выводам отечественной доктрины [2] [3].

В случае несогласия налогоплательщика с вынесенным решением и подачей им жалобы, вышестоящий налоговый орган обязан проверить решение территориального налогового органа с точки зрения законности и обоснованности.

Процедура обжалования решения налогового органа в вышестоящий орган, а также порядок рассмотрения последним жалобы определен, в большинстве своем, положениями статей 137-140 НК РФ [4].

В настоящий момент в судебной практике достаточно часто встречаются споры, в которых налогоплательщики оспаривают решения налоговых органов, действия (бездействия) должностных лиц налоговых органов на том основании, что в рамках процедуры рассмотрения жалоб вышестоящим налоговым органом были допущены существенные нарушения предусмотренной законом процедуры.

Особое место занимают споры, связанные с исследованием вышестоящим налоговым органом обстоятельств, которые не были учтены при принятии решения нижестоящим налоговым органом, или переквалификацией сделок налогоплательщика на стадии рассмотрения жалобы.

При рассмотрении указанных споров возникает принципиальный вопрос о том, является ли принятие вышестоящим налоговым органом новых доказательств или установление новых обстоятельств существенным нарушением процедурно-процессуальных норм налого- вого законодательства, влекущим безусловную отмену судебного акта, или должны быть признаны допустимыми.

Изложенное обосновывает актуальность исследования, направленного на определение правовых последствий действий вышестоящего налогового органа по учету новых доказательств и установлению новых обстоятельств.

Системное толкование положений статей 101, 137, 138, 139.2, 140 НК РФ указывает на то, что вышестоящий налоговый орган проверяет решение нижестоящего налогового органа в определенных пределах - исходя из содержания решения, жалобы, материалов проверки, ограничиваясь предметом проверки, включая пределы проверяемого периоды [3].

Вышестоящий налоговый орган вправе инициировать повторную выездную проверку с целью самостоятельного и полного исследования всех обстоятельств, входящих в предмет проверки. Однако, указанную процедуру следует считать экстраординарной, назначаемой лишь в особых случаях.

Тем не менее, в судебной практике встречаются налоговые споры, в рамках которых налогоплательщики оспаривают решения вышестоящего налогового органа, в случаях, когда такой орган, не назначая повторную выездную проверку, дал иную оценку обстоятельствам, установленным территориальным налоговым органом, или исследовал новые обстоятельства.

Особый интерес при исследовании рассматриваемой категории процедурно-процессуальных нарушений представляет дело ООО «Троицкий элеватор» (А7637290/2017), представленное судебными актами первой, апелляционной и кассационной инстанции [5] [6] [7].

В рамках указанного дела было выяснено, что при рассмотрении апелляционной жалобы вышестоящий орган переоценил установленные в рамках налоговой проверки обстоятельства, сделав самостоятельные выводы относительно деятельности налогоплательщика.

Суды первой и апелляционной инстанции не придали значения указанным процедурно-процессуальным нарушениям, отказав налогоплательщику в удовлетворении его требований.

Однако, суд кассационной инстанции Постановлением АС Уральского округа от 24.07.2019 № Ф09-4289/19 по делу № А76-37290/2017 отменил судебные акты нижестоящих судов и удовлетворив требования налогоплательщика в полном объеме. 
Вместе с тем, обозначенный судебный акт содержит следующий важный вывод:

«Управление Федеральной налоговой службы по Челябинской области, установив фактически новые обстоятельства (вне рамок налогового контроля), которые не были установлены при проведении выездной налоговой проверки и не отражены в акте проверки и решении, принятом по ее результатам, приняло новое решение на основании исследования и оценки иных обстоятельств и доказательств, которое не соответствует действующему налоговому законодательству и нарушает права и законные интересы налогоплательщика.

При таких обстоятельствах оспариваемое решение инспекции с учетом выводов, сделанных управлением, не может быть признано законным и подлежит признанию недействительным» [5].

Обосновывая указанный вывод, суд кассационной инстанции сослался в том числе, на пункт 14 статьи 101 НК РФ, что говорит о признании судом допущенных недостатков существенным процедурно-процессуальным нарушением.

Особое значение указанного прецедента обусловлено тем, что допущенное процедурное нарушение является единственным признанным судом основанием для отмены решения налогового органа, что позволяет говорить о признании судом рассматриваемого процедурно-процессуального нарушения безусловным основанием для отмены ненормативного правового акта налогового органа.

В контексте исследуемой проблемы считается необходимым также выделить выводы суда, сделанные в рамках дела ОАО «Шахта Заречная» (А27-12828/2015), представленного судебными актами первой, апелляционной и кассационной инстанции [8] [9] [10].

Как было установлено судом и отражено в Решении АС Кемеровской области от 16.10.2015 по делу № А2712828/2015 «Управление расширило доказательственную базу, ссылаясь на документы, которые не были проанализированы налоговым органом в ходе проверки, не описаны в оспариваемых решениях и не положены В основу принятия решений» [10].

Учитывая, в частности, изложенный довод, суды первой, апелляционной и кассационной инстанции поддержали налогоплательщика, признав недействительным решение налогового органа об отказе в привлечении налогоплательщика к налоговой ответственности.

Исследуя указанный прецедент, следует также отметить вывод, содержащийся в Постановлении АС Запад-
но-Сибирского округа от 20.05.2016 № Ф04-1972/2016 по делу № A27-12828/2015, и указывающий, что «Управление, ссылаясь в тексте решения на обстоятельства и документы, которые не были проанализированы Инспекцией в ходе проверки, не описаны в оспариваемых решениях и не положены в основу принятия решений, расширило доказательственную базу, а налогоплательщик был лишен возможности оценить их при досудебном порядке урегулирования спора» [8].

Таким образом, в данном случае суд также признает незаконность действий вышестоящего налогового органа по учету в качестве доказательств документов, которые не были исследованы нижестоящим налоговым органом, однако связывает рассматриваемое процедурно-процессуальное нарушение с его последствиями невозможность предоставления налогоплательщиком возражений.

В целом, следует признать обоснованной позицию судов, квалифицирующих переоценку обстоятельств проверки и имеющихся в материалах дела доказательств вышестоящим налоговым органом в качестве существенного процедурно-процессуального нарушения.

Вместе с тем, учитывая императивный характер налогово-правовых норм и обязательность строгого соблюдения налоговых процедур, рассматриваемые нарушения должны признаваться безусловными основаниями для отмены решений налогового органа вне зависимости от возникающих негативных последствий.

В качестве следующего прецедента считается целесообразным рассмотреть дело ООО «Аватель Менеджмент» (А40-79866/2017), представленное судебными актами первой и апелляционной инстанции [11] [12].

В рамках указанного дела территориальный налоговый орган, по итогам выездной налоговой проверки, установил, что налогоплательщик-застройщик получил необоснованную налоговую выгоду в связи с тем, что перечислил определенную сумму денежных средств подрядчику - юридическому лицу. Принимая во внимание то обстоятельство, что объекты недвижимости все-таки были построены и сданы в срок, налоговый орган посчитал, что налогоплательщик-застройщик скрыл являющуюся доходом экономию подрядчика, посредством мнимых взаимоотношений с контрагентами.

Рассматривая жалобу налогоплательщика, вышестоящий налоговый орган вышел за пределы исследования прошедшей выездной налоговой проверки, установив, что налогоплательщик также имеет инвестиционные договоры с физическими лицами, которые в силу современных тенденций судебной практики должны быть 
переквалифицированы в договоры купли-продажи будущей вещи, а денежные средства по ним признаются прибылью налогоплательщика-застройщика.

При этом указанные обстоятельства не анализировались нижестоящим налоговым органом на предмет наличия необоснованной налоговой выгоды и даже в принципе не были отражены в акте налоговой проверки в качестве известных налоговому органу обстоятельств.

Как отмечается в Постановлении Девятого арбитражного апелляционного суда от 01.02.2018 № 09АП-63075/2017 по делу № А40-79866/2017, «переквалификация взаимоотношений и сделок Общества с инвесторами произведена Управлением не только без оценки каких-либо доказательств, подтверждающих ее правомерность, но даже и без их сбора в ходе проверки» [11].

По мнению суда, вышестоящий налоговый орган не вправе был давать оценку инвестиционным договорам с гражданами, так как в первоначальный предмет проверки входили исключительно взаимоотношения застройщика с подрядчиками; материалы налоговой проверки не содержат сведений о содержании и характере взаимоотношений между налогоплательщиком и гражданами-инвесторами.

Кроме того, как установлено судом, вышестоящий налоговый орган также не ознакомил налогоплательщика с расчетами вновь вменяемой недоимки.

В связи с тем, что установление новых обстоятельств проходило вне рамок повторной налоговой проверки, налогоплательщик не имел возможности ознакомиться с новыми выводами вышестоящего налогового органа и, соответственно, представить собственные возражения и объяснения.

На основании изложенного суды первой и апелляционной инстанции признали недействительным решение налогового органа, так как оно принято с существенным нарушением процедурно-процессуальных норм налогового законодательства.

Налоговый орган отказался от обжалования вынесенных судебных актов в порядке кассационного производства.

Рассмотренные налоговые споры позволяют сделать вывод о том, что в настоящий момент суды признают учет вышестоящим налоговым органом обстоятельств и доказательств, которые не были исследованы при принятии решения нижестоящим налоговым органом или переквалификацию сделок налогоплательщика на стадии рассмотрения жалобы в качестве существенного нарушения процедурно-процессуальных положений налогового законодательства, влекущего безусловную отмену решения налогового органа.

Важно отметить, что возможность налогоплательщика обжаловать незаконное и (или) необоснованное решение налогового органа является важной составляющей права на эффективную судебную защиту. Изложенное предопределяет потребность в понятной, последовательной и прозрачной процедуре обжалования.

В научных трудах отмечается, что принцип верховенства права раскрывается в налоговых процедурах преимущественно посредством таких подпринципов как право на доступ к документам (habeas data), право быть выслушанным (audi alteram partem) и право на защиту (ubi ius, ibi remedium) [13].

Следует отметить, что, в частности, указанные подпринципы, обеспечивающие процедурно-процессуальные права участников правоотношений, входят в основу концепции «due process of law» (надлежащая правовая процедура).

Впервые [14] исследуемая концепция получила свое письменное выражение в статье 39 Великой хартии вольностей 1215 года, устанавливающей запрет на применение к человеку определенных санкций в отсутствие законного решения «пэров или/и по праву земли» [15].

В дальнейшем рассматриваемая концепция получила развитие в законодательстве отдельных государств и международных актах. Положения о надлежащей правовой процедуре закреплены в Пятой и Четырнадцатой поправках к Конституции США [16], статье 11 Канадской хартии прав и свобод [17], статье 31 Конституции Японии [18], а также в основных законах иных государств.

Вместе с тем, наибольший интерес для исследования представляют положения Конвенции о защите прав человека и основных свобод, ратифицированной Российской Федерацией [19], а также практика их применения.

Статья 6 Конвенции о защите прав человека и основных свобод [20] содержит совокупность положений, направленных на обеспечение права на справедливое судебное разбирательство.

Зарубежные ученые-правоведы, указывают на применимость обозначенных положений Конвенции о защите прав человека [20] и основных свобод к налоговым спорам, разрешаемым в судебном или административном порядке [13]. 
Следует согласиться с указанной точкой зрения в силу расширительного толкования положений статьи 6 Конвенции о защите прав человека и основных свобод [20] в части их применения к спорам, связанным с уголовным обвинением, что подтверждается релевантной практикой ЕСПЧ. Положение о том, что «Каждый в случае спора ... при предъявлении ему любого уголовного обвинения» толкуется ЕСПЧ в качестве основания применения статьи 6 Конвенции о защите прав человека и основных свобод также и к иным публично-правовым спорам [21] [22] [23] [24] [25] [26] [27].

Принимая во внимание общие исторические и нормативно-правовые начала, процедура реализации «права на защиту» в различных государствах представляется весьма схожей. Процедуры обжалования решения налогового органа разных юрисдикций отличаются, в большинстве своем, сроками подачи жалоб, этапами рассмотрения возражений или основаниями для подачи жалоб [28].

При этом в каждой юрисдикции сформировались свои собственные правила или правоприменительные подходы относительно допустимости исследования и учета вышестоящим налоговым органом новых доказательств.

Например, в Республике Польша в соответствии со статьей 229 The Tax Ordinance Act [29] вышестоящий налоговый орган вправе осуществить сбор новых доказательств.

Вместе с тем, современная доктрина не имеет единого мнения относительно представленных полномочий вышестоящего налогового органа.

К. Тешнер, в частности, указывает на допустимость принятия вышестоящим налоговым органом новых доказательств, в случае если указанные доказательства необходимы для целей принятия правильного и справедливого решения, что соответствует ранее упомянутому процессуальному принципу объективной истины. При этом, по мнению автора, вышестоящий налоговый орган не вправе подменять собой первую инстанцию и начинать новое производство, выражающееся в сборе доказательств, оформлении материалов проверки и принятии решения [30].

Другого мнения придерживается Б. Адамяк, утверждающая о том, что вышестоящий налоговый орган не вправе осуществлять деятельность по самостоятельному сбору доказательств, вне зависимости от каких-либо обстоятельств [31].

Законодательство Литовской Республики, в свою, очередь исходит из прямого запрета на учет и оценку вышестоящим налоговым органом (Комиссией по налоговым спорам) доказательств, не раскрытых перед центральным налоговым администратором при принятии первоначального решения [32]. Исключением является предоставление доказательств налогоплательщиком при подтверждении им объективной невозможности предоставления доказательств до принятия решения при первоначальном рассмотрении.

Анализ судебной практики российских судов, а также исследование правового регулирования в отдельных европейских государствах, указывает на то, что по общему правилу вышестоящий налоговый орган не должен подменять собой «первую административную инстанцию» и осуществлять сбор и исследование новых доказательств.

На основании изложенного, в частности, доминирующей судебной практики и положений действующего законодательства, можно согласиться с выводом о том, что установление вышестоящим налоговым органом принципиально новых доказательств / и отражение данных новых фактов в своем решении (то есть фактов, информация о которых не содержалась ни в акте, ни в решении нижестоящего органа) признается существенным нарушением процедурно-процессуальных норм налогового законодательства, которое, как правило, может повлечь отмену решения соответствующего налогового органа.

\section{ЛИТЕРАТУРА}

1. Постановление Конституционного Суда РФ от 14.07.2005 № 9-П «По делу о проверке конституционности положений статьи 113 Налогового кодекса Российской Федерации в связи с жалобой гражданки Г.А. Поляковой и запросом Федерального арбитражного суда Московского округа» // СПС «КонсультантПлюс».

2. Vinnitskiy D.V. Tax Procedures: Russian National Report. IBFD: 2019 EATLP Congress. Amsterdam, the Netherlands 2019 preprint's URL: http://www.eatlp.org/ uploads/public/2019/National\%20Report\%20Russia.pdf (Дата обращения: 26.03.2021).

3. Черепанов С.А. Повторная выездная налоговая проверка как пример несовершенства процедурных норм Налогового кодекса РФ // Налоговед. 2019. № 11. C. 21-31.

4. «Налоговый кодекс Российской Федерации (часть первая)» от 31.07.1998 № 146-Ф3 (с посл. изм. и доп. на 20.07.2020) // СПС «КонсультантПлюс».

5. Постановление АС Уральского округа от 24.07.2019 № Ф09-4289/19 по делу № А76-37290/2017 // СПС «КонсультантПлюс». 
6. Постановление Восемнадцатого арбитражного апелляционного суда от 09.04.2019 № 18АП-2387/2019 по делу № А76-37290/2017 // СПС «КонсультантПлюс».

7. Решение АС Челябинской области от 11.01 .2019 по делу № A76-37290/2017 // СПС «КонсультантПлюс».

8. Постановление АС Западно-Сибирского округа от 20.05.2016 № Ф04-1972/2016 по делу № А27-12828/2015 // СПС «КонсультантПлюс».

9. Постановление Седьмого арбитражного апелляционного суда от 07АП-11797/2015 по делу № А27-12828/2015 // СПС «КонсультантПлюс».

10. Решение АС Кемеровской области от 16.10.2015 по делу № А27-12828/2015 // СПС «КонсультантПлюс».

11. Постановление Девятого арбитражного апелляционного суда от 01.02.2018 № 09АП-63075/2017 по делу № А40-79866/2017 // СПС «КонсультантПлюс».

12. Решение АС города Москвы от 21.09.2017 № А40-79866/2017 // СПС «КонсультантПлюс».

13. Проф. Дж. Кокотт, проф., д.ю.н. П. Пистоне, Р. Миллер, Международное публичное право и налоговое право / Научн. ред. перевода на русский и предисловие проф., Д.Ю.н. Д.В. Виннцкого, Издание УрГЮУ и Института права БРИКС, Екатеринбург, 2021. - 114 с.

14. Burns R.E. Due Process of Law: After 1890 Anything; Today Everything — A Bicentennial Proposal to Restore Its Original Meaning. DePaul L. Rev. 773 (1986). pp. 774-823.

15. Памятники истории Англии XI-XIII Вв.: русский и латинский тексты Великой хартии вольностей и других документов / пер. [с лат.] и введение Д.М. Петрушевского; Мос. гос. ун-т им. М.В. Ломоносова, Ист. фак. — М.: [б. и.], 1936. - 238.

16. Willis H.E. Due Process of Law Under the United States Constitution // Articles by Maurer Faculty. — 1926. — Paper 1249. — pp. 331-345.

17. Dodek A.M. Canada as a Constitutional Exporter: The Rise of the «Canadian Model» of Constitutionalism / A.M. Dodek // Supreme Court Law Review. 2nd Series. 2007. Vol.36. pp. 309-323.

18. Yuji Iwasawa/ International law, Human Rights, And Japanese Law. Oxford: Clarendon Press. 1998. p. 398.

19. Федеральный закон от 30.03.1998 № 54-Ф3 «0 ратификации Конвенции о защите прав человека и основных свобод и Протоколов к ней» // СПС «КонсультантПлюс».

20. «Конвенция о защите прав человека и основных свобод» (Заключена в г. Риме 04.11.1950) (с изм. от 13.05.2004) (вместе с «Протоколом [№ 1]» (Подписан В г. Париже 20.03.1952), «Протоколом № 4 об обеспечении некоторых прав и свобод помимо тех, которые уже включены в Конвенцию и первый Протокол к ней» (Подписан В г. Страсбурге 16.09.1963), «Протоколом № 7» (Подписан В г. (трасбурге 22.11.1984)) // СПС «КонсультантПлюс».

21. Постановление ЕСПЧ от 04.05.2017 по делу «Компания «Чап Лтд.» (Chap Ltd.) против Армении» (жалоба № 15485/09) // СПС «КонсультантПлюс».

22. Постановление ЕСПЧ от 07.06.2012 по делу «Сегам СА» (Segame SA) против Франции» (жалоба № 4837/06) // СПС «КонсультантПлюс».

23. Постановление ЕСПЧ от 20.09.2011 «Дело «ОАО «Нефтяная компания «Юкос» (ОАО Neftyanaya Kompaniya «Үukos») против Российской Федерации» (жалоба № 14902/04) // СПС «КонсультантПлюс».

24. Постановление ЕСПЧ от 31.07.2014 «Дело «ОАО «Нефтяная компания «Юкос» (ОАО Neftyanaya Kompaniya «Yukos») против Российской Федерации» (жалоба № 14902/04) // СПС «КонсультантПлюс».

25. Постановление ЕСПЧ от 21.02.2008 по делу «Равон и другие (Ravon and Others) против Франции» (жалоба № 18497/03) // СПС «КонсультантПлюс».

26. Постановление ЕСПЧ от 23.11.2006 по делу «Юссила (Jussila) против Финляндии» (жалоба № 73053/01)

27. Постановление ЕСПЧ от 24.02.1994 по делу «Банденун против Франции» (жалоба № 12547/86) // СПС «КонсультантПлюс».

28. Lang M., Pistone P., Schuch J., Staringer C., Procedural Rules in Tax Law in the Context of European Union and Domestic Law, Kluwer Law International, 2010, pp. 752, (English).

29. The Tax Ordinance Act $z$ dnia 29 sierpnia 1997 r. (Dz.U. tłum. gb Nr 137, poz. 926) URL: https://supertrans2014.files.wordpress.com/2014/06/the-tax-ordinance-act. pdf (Дата обращения 19.03.2021).

30. Krzysztof Tesner. Administrative Body as an Entity Applying the Law in the Tax Appeal in Problems of application of tax law in Central and Eastern European countries //Проблемы налогового правоприменения в странах Центральной и Восточной Европы. Омск: Изд-во Ом. гос. ун-та, 2013. С. 66-78.

31. B. Adamiak. Prawo procesowe administracyjne. System Prawa Administracyjnego, t. 9, red. R. Hauser, Z. Niewiadomski, A. Wróbel. Warszawa. 2010. P. 218.

32. Bronius Sudavicius. Evidence and Proof in Resolving of Tax Disputes in the Lithuania //Проблемы налогового правоприменения в странах Центральной и Восточной Европы. Омск: Изд-во Ом. гос. ун-та, 2013. С. 114-122.

(c) Зимулькин Максим Игоревич ( mi.zimulkin@gmail.com ).

Журнал «Современная наука: актуальные проблемы теории и практики» 